\title{
Role of transvaginal sonography in the detection of endometrial carcinoma
}

\author{
Showkat MS ${ }^{1}$, Nabi $\mathrm{S}^{3}$, Khondker L ${ }^{2}$, Bhowmik B ${ }^{1}$, Tushar $\mathrm{SN}^{4}$, Jahan $\mathrm{MU}^{1}$ \\ ${ }^{I}$ Department of Radiology and Imaging, Bangabandhu Sheikh Mujib Medical University (BSMMU), Dhaka, \\ ${ }^{2}$ Department of Dermatology, Bangabandhu Sheikh Mujib Medical University (BSMMU), Dhaka, ${ }^{3}$ Department \\ of Radiology and Imaging, Dhaka Medical College (DMC), Dhaka, ${ }^{4}$ Green Life Medical College and Hospital, \\ Dhaka,Email: drjany2008@yahoo.co.uk
}

\begin{abstract}
Transvagival sonography is superior to transabdominal sonography in most cases of pelvic pathology. Objective of this study is to evaluate the clinical usefulness of transvaginal ultrasonography (TVS) in pre, peri and post menopausal women suspected to have endometrial carcinoma. This cross sectional study was done with 40 patients who are clinically suspected having thickened endometrium. The study was carried out January 2007 to November 2008 for a period of two years. The patients having endometrial carcinoma diagnosed by TVS was correlated with histopathological diagnosis following collection of the report from the respective cases. Of total 40 cases, 2(5.0\%) cases were endometrial carcinoma and 38(95.0\%) were negative for endometrial carcinoma respectively in TVS findings. On the other hand $3(7.5 \%)$ cases were endometrial carcinoma and $37(92.5 \%)$ cases were negative for endometrial carcinoma in histopathological findings. The validity of TVS in diagnosis of endometrial carcinoma were studied by calculating sensitivity, specificity, accuracy, positive predictive value and negative predictive value, which were 67 percent, 100 percent, 98 percent, 100 percent and 97 percent respectively. As the TVS findings of the present study correlated well with the histopathology findings and the validity test values were higher than observed by others, it can be concluded that TVS is sensitive and accurate modality in the evaluation of endometrial carcinoma.
\end{abstract}

\section{Introduction}

Endometrial carcinoma is the most common invasive cancer of the female genital tract and accounts for $7 \%$ of all invasive cancer in women, excluding skin cancer. At one time, it was far less common than cancer of the cervix, but earlier detection of endometrial carcinomas in younger age groups have reversed this ratio. There are now 34,000 new endometrial cancers per year, compared with 13,000 new invasive cervical cancers $^{1}$. Country wide extrapolated statistics in Bangladesh showed extrapolated incidence of endometrial cancer is 20,421 and cervical cancer is 10,600 when $141,340,476^{2}$ population estimated used $^{2}$. Despite their high frequency, endometrial cancer arises mainly in postmenopausal women, causing abnormal (postmenopausal) bleeding. This permits early detection and cure at an early stage ${ }^{1}$. Incidence and pathogenesis of carcinoma of the endometrium is uncommon in women younger than 40 years. There higher frequency of this form of neoplasia is seen with obesity, diabetes (abnormal glucose tolerance is found in more than $60 \%$ ), hypertension and infertility ${ }^{3}$. On histologic examination, most endometrial carcinomas (about $85 \%$ ) are adenocarcinomas characterized by more or less well defined gland patterns lined by malignant stratified columnar epithelial cells ${ }^{4}$.

Most endometrial malignancies are adenocarcinomas. Transvaginal examination is helpful in screening for early changes of endometrial hyperplasia or carcinoma by accurately measuring thickness. Recent studies of patients with post menopausal bleeding show that an endometrial thickness (double layer) less than 5 $\mathrm{mm}$ reliably exclude significant endometrial abnormality. At present, most investigators believe all symptomatic patients should be biopsied. However transvaginal ultrasonography may be used to follow symptomatic patients with normal endometrial thickness in whom biopsy is contraindicated or who do not wish to undergo an invasive procedure. Demonstration of myometrial invasion is clear evidence for endometrial carcinoma. Transvaginal ultrasonography demonstrates myometrial invasion as thickening 
and irregularity of the central endometrial interface with echogenic or hypoechoic patterns combined with infiltration of hyperechoic structures in the myometrium ${ }^{5}$.

An abnormally thick, irregular or indistinct endometrium is often seen at pelvic ultrasound compared to transabdominal ultrasound, TVS allows for improved resolution of the endometrium and adnexa due to close proximity of high resolution transducer to the pelvic organs. The absence of the full bladder which compresses the uterus enhances this improvement and allows the measurement of the atrophic endometrium as well as detection of intracavitary lesions ${ }^{6}$. Measurement of endometrial thickness using TVS is helpful in diagnosis of endometrial pathology, including endometrial cancer and in assessment of myometrial invasion ${ }^{6}$. For TVS the sensitivity and specificity versus endometrial pathology were $73.9 \%$ and $73.7 \%$ respectively in Cacciatore et al. study while they were $73.9 \%$ and $95.7 \%$ in ElMowafi et $\mathrm{al}^{\mathbf{7 , 8}}$.

Another study shows that TVS allows detection of an endometrial pathology in the vast majority of cases and as it is easy, relatively cheap, needs no anaesthesia and non-invasive. It can be used as the first diagnostic step in the investigations of women with postmenopausal bleeding ${ }^{7}$. For the direct diagnosis of endometrial pathology, TVS can reach a higher sensitivity once endometrial thickness is taken into account 9 . Transvaginal ultrasonography is as effective as the D\&C (Dilatation and Curettage) for depicting the endometrium in pre, peri and post menopausal women with irregular bleedings ${ }^{10}$. On the basis of above facts this study is designed to establish the role of TVS as a sensitive tool used for evaluation of endometrial carcinoma.

\section{Materials and Methods}

This cross sectional study was carried out with forty patients who are clinically suspected having thickened endometrium during duration of 2 years to confirm the clinical diagnosis. Clinically suspected patients from Department of Obstetrics \& Gynaecology suffering from endometrial pathology were referred to Department of Radiology \& Imaging of BSMMU, before performing D\&C (Dilatation \& curettage) \& Hysterectomy. The study was carried out in the Department of Radiology and Imaging BSMMU in collaboration with the Department of Obs \& Gynecology, Pathology and Histopathology of the same institute for cytopathological correlation. The study was carried out January 2007 to November
2008 a period of two years. All the information were collected in a pre-designed structured data collection sheet. Sampling method was purposive type of non-probability sampling. At BSMMU TVS were performed with $6.5 \mathrm{MHz}$ or $7.5 \mathrm{MHz}$ multifrequency convex transvaginal probe and all TVS report were interpreted by the investigator initially and then were reviewed by the Head of the Department of Radiology \& Imaging of BSMMU. Inclusion criterias of selection of patients were i) Pre, peri and post menopausal women with abnormal uterine bleeding for more than 6 months who were clinically suspected to have endometrial pathology. ii) Patients with abnormally thickened endometrium $(>15 \mathrm{~mm}$ in premenopausal women and $>5 \mathrm{~mm}$ in postmenopausal women) detected on transabdominal ultrasonography or Tranavaginal sonography. Exclusion criterias of selection of patients were i) patients having AUB due to causes other than endometrial pathology and ii) patients who were unfit or unwilling to do TVS.

Ethical consideration: Prior to the commencement of this study, the research protocol was approved by the institutional review board (IRB). The aims and objectives of the study along with its procedure, alternative diagnostic methods, risks and benefits of this study were explained to the patients in easily understandable local language and then informed written consent was taken from each patient. It was assured that all informed records would be kept confidential and the procedure would be helpful for both the physicians and the patients in making rational approach of the case management.

TVS techniques: TVS was carried out with 6.5 $\mathrm{MHz}$ or $7.5 \mathrm{MHz}$ multi-frequency convex transvaginal probe. Sagital and coronal TVS images of uterus were obtained in all patients. Double layer thickness was determined on a mid sagital view. Endometrial thickness $<5 \mathrm{~mm}$ was used as the cut off level for abnormality in postmenopausal patients and $<15 \mathrm{~mm}$ in premenopausal patients. At first patient should be given a brief explanation of the ultrasonographic procedure. The pelvic ultrasonographic examination is generally performed in specific ultrasound room equipped with a gynaecologic examining table. Written informed consent from the patient should be taken. The patient should empty her urinary bladder before examination started. The patient is allowed to be undressed from down in private. She should be prepared by a nursing assistant in lithotomy position in a pillow in the back and draped with a sheet.

The vaginal probe is covered with condom or a glove. Coupler is needed to decrease the acoustic 
impedence as sound leaves the transducer and enters the body. Even a small amount of air between the transducer and the body will result in marked sound attenuation and artifacts. To acoustically couple the transducer to the vaginal mucosa, jelly is placed into a condom. Additional lubricant is placed on the surface of the condom to serve as an acoustic coupler between the condom and patient. The transducer is gently placed into the vagina and advanced to the level of the vaginal fornix and the examination begins. Probe orientation- most transvaginal transducers are marked to help orient the probe. When the transducer is oriented or held so that the sound beam is being directed across the pelvis from side to side, a transpelvic (T-pelvic) plane is being imaged. Rotating the transducer 90 degrees will direct the sound beam anteriorly and posteriorly in the pelvis, giving an anterior-posterior plane (a-p pelvic) plane image. A $\mathrm{T}$ pelvic image and an AP pelvic image of the uterus and ovaries are obtained and recorded with biometric measurements during each examination. Oblique images can also be obtained, as needed by rotating the probe ${ }^{\mathbf{1 1}}$.

Data Collection: Written consent was taken from all the patients after informing the necessary informations regarding the research study. Then data were collected in a pre-designed structured data collection sheets. Data were collected from primary source starting from the clinical history and physical examination, TVS findings. The patients were than followed up to histopathological diagnosis of endometrial curettage and/ or hysterectomy specimen.

Statistical Analysis of Data: All the relevant collected data were compiled on a master chart first. Then organized by using scientific calculator and standard statistical formulas. Percentages were calculated to find-out the proportion of the findings. Further statistical analyses of the results were done by computer software device as statistical packages for social scientist (SPSS). The results were presented in tables, figures, diagrams etc. For the validity of the study outcome, sensitivity, specificity, accuracy, positive and negative predictive values of the TVS findings in the diagnosis of endometrial pathology were calculated after confirmation of the diagnosis by histopathology and were calculated by standard formula. For significance of differences Fisher's exact test, Chi test were done where applicable. A " $p$ " value $<0.05$ was considered as significant.

\section{Results}

A total of 40 consecutive cases were selected who were attendant in the department of Radiology and
Imaging BSMMU with clinically diagnosed endometrial pathology. Histopathological examination was done from respective pathology department and the TVS findings were correlated with histopathological findings. The mean \pm SD age of the patients was $42.3 \pm 6.7$ years. The maximum patients were 41 to 50 years age group and least was in 51 to 60 years age group. The most common symptoms associated with endometrial pathology were abnormal uterine bleeding present in all forty cases $(100.0 \%)$. Eighteen patients $(45.0 \%)$ had lower abdominal pain. Ten cases $(25.0 \%)$ had infertility. Dysmenorrhea was present among 5 patients $(12.5 \%)$. These results are shown in table I.

Table I: Distribution of the patients by age and clinical features $(n=40)$

\begin{tabular}{lcc}
\hline Age in year & Number of patients & Percentage \\
\hline $30-40$ & 16 & 40.0 \\
$41-50$ & 18 & 45.0 \\
$51-60$ & 6 & 15.0 \\
Clinical Features & Number of patients & Percentage \\
PV bleeding & 40 & 100.0 \\
Lower abdominal pain & 18 & 45.0 \\
Infertility/ subfertility & 10 & 25.0 \\
Dysmenorrhea & 5 & 12.5 \\
\hline
\end{tabular}

Mean $\pm \mathrm{SD}=42.3 \pm 6.7$

Among 40 patients of present series the most common diagnosis was endometrial hyperplasia which included 18 cases $(45.0 \%)$ most of this appeared as diffuse and homogenous thickening of echogenic endometrium on TVS. The results are shown in figure 2.

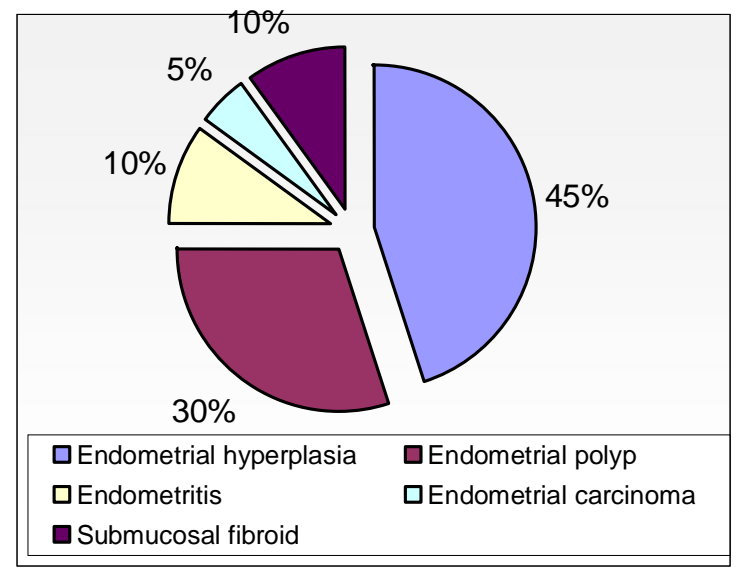

Fig. 2: Showing TVS findings of endometrial pathology

In this study among 40 patients, the most common diagnosed endometrial pathology was endometrial hyperplasia 17 patients (42.5\%). Endometrial polyp was diagnosed in 13 patients (32.5\%). Endometrial carcinoma was in 3 patients $(7.5 \%)$ and Submucosal fibroid was in 4 patients $(10.0 \%)$, these results are shown in figure 3 . 


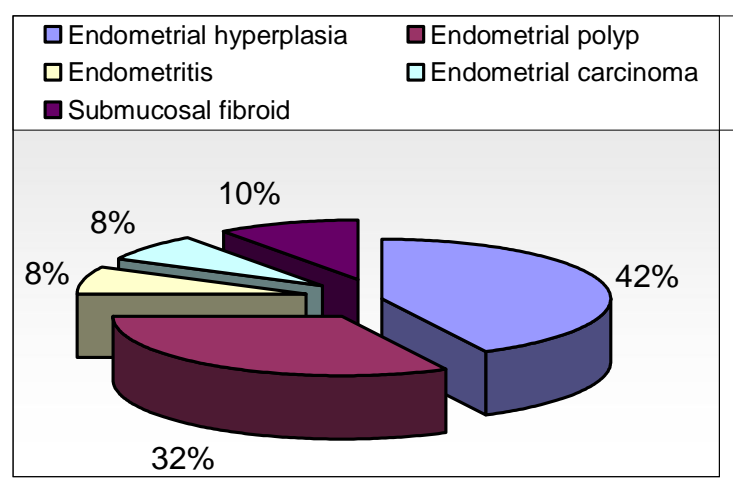

Fig 3: Showing Histopathological diagnosis of different endometrial pathology

The patients having endometrial carcinoma diagnosed by TVS was correlated with histopathological diagnosis following collection of the report from the respective cases. Of total 40 cases, $2(5.0 \%)$ cases were endometrial carcinoma and $38(95.0 \%)$ were negative for endometrial carcinoma respectively in TVS findings. None was found as negative for endometrial carcinoma in histopathology among the all suspected endometrial carcinoma, which were diagnosed by TVS. On the other hand $3(7.5 \%)$ cases were endometrial carcinoma and 37 (92.5\%) cases were negative for endometrial carcinoma in histopathological findings. Among 38 negative for endometrial carcinoma cases which were diagnosed by TVS, 1 case was endometrial carcinoma and the rest 37 cases were negative for endometrial carcinoma in histopathological findings. The result is shown table II. The validity of TVS and histopathological findings were confirmed by calculating sensitivity, specificity, accuracy, positive and negative predictive values by using the standard formula which were 67 percent, 100 percent, 98 percent, 100 percent and 97 percent respectively.

Table II: Analysis of TVS and histopathological findings of endometrial carcinoma.

\begin{tabular}{lccc}
\hline Ultrasonographic diagnosis & \multicolumn{2}{c}{ Histopathological diagnosis } & \\
\cline { 2 - 3 } & $\begin{array}{c}\text { positive for } \\
\text { endometrial } \\
\text { carcinoma }\end{array}$ & $\begin{array}{c}\text { negative for } \\
\text { endometrial } \\
\text { carcinoma }\end{array}$ & Total \\
\hline $\begin{array}{l}\text { Suspected for endometrial } \\
\text { carcinoma }\end{array}$ & 2 & 0 & 2 \\
$\begin{array}{l}\text { Suspected for negative for } \\
\text { endometrial carcinoma }\end{array}$ & 1 & 37 & 38 \\
\begin{tabular}{l} 
Total \\
\hline
\end{tabular} & 3 & 37 & 40 \\
\hline
\end{tabular}

Fisher's exact test, Chi value $=28.82, \mathrm{df}=1, \mathrm{p}=0.001$

\section{Discussion}

Khatun et al. in a study have shown 62 patients of 30 to 70 years of age with abnormal uterine bleeding $^{12}$. Patients were evaluated by TVS and most $(48.39 \%)$ of the patients belongs to $41-50$ years age group, which is closely resemble with the present study, where the mean $\pm \mathrm{SD}$ age of the patients having endometrial diseases was $42.3 \pm 6.7$ years and the maximum patients belongs to $41-50$ years age group and least was in 51 to 60 years age group. Similarly, Mathew et al. observed the identical age range from 20 to 65 years and maximum number was from 41 to 50 years of age $^{12}$. El-Mowafi et al. has observed higher mean age in Egypt women having postmenopausal bleeding, which was $52.6+2.8$ years, range $48-58$ years ${ }^{8}$. Similarly, Leverro et al and Tsikouras et al. have observed mean age of the patients 63 years (ranging from 52 to 70 years) and 58.5 years (ranging from 52 to 65 years) respectively ${ }^{4,14}$. On the other hand, Wilailak et al. has observed the mean age 55.93 years ranged from $42-80$ years $^{15}$. Maia et al. observed on 47 menopausal patients aged ranged from 42 to 72 years ${ }^{16}$. In the present study it was observed that the most common presenting symptoms associated with endometrial pathology of the $100 \%$ patients had abnormal uterine bleeding, $45.0 \%$ had lower abdominal pain, $25.0 \%$ had infertility and $12.5 \%$ had dysmenorrhea. Maia et al. reported that post menopausal bleeding was main symptom.

El-Mowafi et al. observed in their histopathological diagnosis that out of 42 cases showed normal postmenopausal atrophic endometrium in 19 cases (45.2\%) and chronic endocervicitis was diagnosed in 5 of them ${ }^{8}$. An endometrial pathology was found in 23 patients (54.8\%), endometrial hyperplasia was diagnosed in 8 cases (19\%), a polyp was found in 11 cases $(26.2 \%)$, endometritis was found in 2 cases $(4.8 \%)$ and endometrial carcinoma was the histopathological report of 2 cases $(4.8 \%)$. Endometrial echoes were visualised and measured by TVS in all cases. An abnormal endometrial texture was found in 17 of the 23 cases with endometrial pathology (sensitivity 73.9\%). Hyperplasia was diagnosed in 7 of the 8 cases, while the other case was diagnosed as normal atrophic endometrium. A polyp was diagnosed in 9 cases of the 11, while the other 2 cases were diagnosed as normal atrophic endometrium. The 2 cases of endometritis were diagnosed by TVS as hyperplasia. Maia et al found endometrial hyperplasia was in 10 patients, all of them had abnormal uterine bleeding ${ }^{16}$. The results of above authors are comparable with the present study findings. According to histopathological diagnosis of different endometrial pathology in this study it was observed that the most common diagnosed endometrial pathology was endometrial hyperplasia $42.5 \%$ were diagnosed as endometrial hyperplasia. 
Endometrial polyp was diagnosed in $12.5 \%$ cases, endometrial carcinoma in $7.5 \%$ cases and submucosal fibroid was in $10.0 \%$ cases. Mathew et al. found in their study that endometrial hyperplasia was $18.2 \%$, endometrial polyp was diagnosed in $39.1 \%$ cases and endometrial carcinoma in $0.9 \%$ cases in histopathological diagnosis ${ }^{13}$. Wilailak et al. found in their study that endometrial hyperplasia was $17.3 \%$ and endometrial polyp was diagnosed in $4.9 \%$ cases in histopathological diagnosis ${ }^{15}$. Tsikouras et al. observed on 123 postmenopausal women with suspicious endometrium $>5 \mathrm{~mm}$, endometrial polyps was $7.13 \%$, one cervical polyp with extension in the cavity $0.8 \%$, endometrial atrophies $73.1 \%$, atrophic endometritis $8.13 \%$, hyperplasia $1.62 \%$ and hyperplasia with atypia was $0.8 \%{ }^{14}$.

Sensitivity of Transvaginal ultrasonography (TVS) phase in diagnosis endometrial carcinoma was $67.0 \%$, specificity $100.0 \%$, accuracy $98.0 \%$, positive predictive values $100.0 \%$ and negative predictive values $97.0 \%$ in the present study. Olaya et al. observed that the sensitivity of Transvaginal ultrasonography (TVS) phase in diagnosis endometrial carcinoma was $94.1 \%$, specificity $84.8 \%$ and overall accuracy $88.0 \%{ }^{17}$. Mathew et al. have observed the sensitivity of Transvaginal ultrasonography (TVS) in diagnosis of abnormal uterine bleeding was $54.0 \%$, specificity $100.0 \%$, accuracy $84.5 \%$, positive predictive values $100.0 \%$ and negative predictive values $81.1 \%^{13}$. Khatun et al have observed the sensitivity of Transvaginal ultrasonography (TVS) in diagnosis of cause of abnormal uterine bleeding was $95.5 \%$, specificity $82.3 \%$, accuracy $91.9 \%$, positive predictive values $93.5 \%$ and negative predictive values $87.5 \%$. Almost similar value was obtained by Grigoriou et al. where sensitivity was $98.2 \%$, specificity $97.8 \%$ and positive predictive values $93.7 \%$ and negative predictive values $87.5 \%{ }^{\mathbf{1 8}}$. Loverro et al have observed the sensitivity (normal+benign pathology versus malignant pathology) was $97.5 \%$, specificity 100\% (normal+benign pathology versus malignant pathology $)^{4}$. We recognize that there are limitations of vaginal ultrasonography in the postmenopausal patient. It can be technically difficult to perform if the introitus has become stenotic. Coexisting myomas can obscure the visualization of the endometrial echo. Proliferative endometrium, although not conventionally thought of as 'pathologic' are certainly not normal in a post menopausal group.

Conclusion: As the TVS findings of the present study correlated well with the histopathology findings and the validity test values were higher than observed by others it can be concluded that
TVS is sensitive and accurate modality in the evaluation of endometrial carcinoma. MRI of female pelvis could be added as an additional modality where necessary especially for staging in endometrial carcinoma.

\section{References}

1. Karampl E, Bourne T, Hurlen Solbakken H, Istre O. Transvaginal ultrasonography, sonohysterography and operative Hysteroscopy for the evaluation of abnormal uterine bleeding. Acta Obstet Gynaecol Scand 2001; 80 (7): 616-22.

2. Right diagnosis from healthgrades. US Census Bureau, population estimate 2004. (last updated march 2013). URL: http://www.rightdiagnosis.com/e/endometrial_ cancer/stats-country.htm.

3. Mencaglia L, Perino A, Hamou J. Hysteroscopy in perimenopausal and post menopausal women with abnormal uterine bleeding. J Reprod Med 2007; 32: $577-582$.

4. Loverro G, Bettocchi S, Pansini N, Porreca MR, Selvaggi L. Hyperplastic human endometrium. J Am Assoc Gynaecol Laparosc 2006; 3(4): 27.

5. Qureshi IA, Ullah H, Akram MH, Ashfaq S, Nayyar S. Transvaginal versus transabdominal sonography in the evaluation of pelvic pathology. J Coll Physicians Surg Pak 2004; 14(7): 390-3.

6. Crofton M. Gynecological Imaging. Sutton D (editor) Text book of Radiology and Imaging. $7^{\text {th }}$ edition, London: Churchill Livingstone; 2003. 1069-1105.

7. Cacciatore B, Ramsoy T, Lehtoirta P and Ylostalo P. Transvaginal sonography and hysteroscopy in postmenopausal bleeding. Acta Obstet Gynecol Scand 2004; 73: 413-16.

8. El-Mowafi D, Farid A and El-Badawi A. Transvaginal Sonography and Hysteroscopy Versus Histopathology in Postmenopausal Bleeding. Obstetrics and Gynecology, Radiology and Pathology Departments, Benha Faculty of Medicine. Eygpt 2005; gfmer.ch/ International_activities_En/.../Transvaginal_ sonography. htm 4/9/2008.

9. Goldstein S. Use of ultrasonohysterography for diagnosis of perimenopausal patients with unexplained uterine bleeding. Am. J. Obstet Gynecol 2004; 170: 565-70.

10. Bakos O, Heimer G. Transvaginal Ultrasonographic Evaluation of the Endometrium Related to the Histological Findings in Pre- and imenopausal Women. Gynecologic and Obstetric Investigation 2004; 45: 199-204.

11. Andrews HS. Uterine pathology. Deubury K, Meire $\mathrm{H}$, Cosgrove D (editors). Ultrasound in Obstetrics and Gynecology. $2^{\text {nd }}$ ed, Churchill Livingstone; 2003. 29-33. 
12. Khatun A, Ahsan S, Mohiuddin AS, Sadeque ASQ, Akhter S, Hassain I, Azad SL, Ahmed AU, Rahman SM and Rahman M. Role of Transvaginal sonography in the evaluation of abnormal uterine bleeding with histopathological correlation. Bangladesh Journal of Radiology and Imaging 2003; 11(1): 14-17.

13. Mathew M, Gupta R, Krolikowski A. Role of transvaginal ultrasonograpy and diagnostic hysteroscopy in the evaluation of patients with abnormal uterine bleeding. International Journal of Gynecology and Obstetrics 2000; 71: 251-253.

14. Tsikouras P, Galazios G, Liberis V, Bouzaki A, Grapsas X, Maroulis G. TV sonographic assessment in postmenopausal asymptomatic women. Eur J Gynaecol Oncol 2007; 28(6): 473-6.

15. Wilailak S, Jirapinyo M, Theppisai U. Transvaginal Doppler sonography: is there a role for this modality in the evaluation of women with postmenopausal bleeding? The European Menopause Journal 2005: 50: 111-16.

16. Maia H, Barbosa IC, Farias JP, Ladipo OA, Coutinho EM. Evaluation of the endometrial cavity during menopause. International Journal of Gynecology \& Obstetrics 2006; 52: 61-66.

17. Olaya FJ, Dualde D, García E, Vidal P, Labrador T, Martínez F et al. Transvaginal sonography in endometrial carcinoma: preoperative assessment of the depth of myometrial invasion in 50 cases. Eur J Radiol 2004; 26(3): 274-9.

18. Grigoriou O, Kalovidouros A, Papadias C, Antoniou G, Antonaki V, Giannikos L. Transvaginal sonography of the endometrium in women with postmenopausal bleeding. Journal of the climacteric and postmenopause 1996; 23: 9-14. 